\title{
EXTRAÇÃO DO ÓLEO ESSENCIAL DA AMÊNDOA DO BUTIÁ CAPITATA
}

\section{P. F. MARTINS ${ }^{1}$, M. BOTTEGA ${ }^{1}$, O. W. PIETSCH JR ${ }^{1}$, J. M. M. de MELLO ${ }^{1}$, F. DALCANTON $^{1}$}

${ }^{1}$ Universidade Comunitária da Região de Chapecó, Área de Ciências Exatas e Ambientais E-mail para contato: prifabiola@unochapeco.edu.br

\begin{abstract}
RESUMO - O estudo da extração do óleo presente na amêndoa do Butiá capitata é importante para o melhor aproveitamento da fruta na agroindústria. O objetivo deste trabalho foi avaliar a extração do óleo da amêndoa do Butiá capitata pelo método de Soxhlet, comparando a sua rentabilidade e variando-se o solvente e o tempo de extração. Foram coletados butiás provenientes do município de Erechim/RS. Foi realizada a separação manual da polpa, do caroço e a quebra do mesmo para a obtenção das amêndoas. No método de extração por Soxhlet utilizou-se hexano e etanol como solventes, durante o período de 30 e 60 minutos. O maior rendimento de óleo da amêndoa foi obtido com etanol em um tempo de extração de 60 minutos, sendo este de $38,80 \pm 1 \%$. O óleo essencial do Butiá tem demonstrado um considerável potencial em aplicações industriais, devido ao fato de apresentar significativa atividade antimicrobiana e por ser rico em ácidos graxos de cadeia média e longa.
\end{abstract}

Palavras chaves: Butiá capitata, extração Soxhlet, rendimento.

\section{INTRODUÇÃO}

O Butiazeiro (Butiá capitata) pertence a um pequeno gênero de palmeiras subtropicais, ocorrem naturalmente no sul do Brasil, porém, encontra-se em diversas partes do mundo. A espécie é a mais cultivada nos Estados Unidos da América do Norte. Por se tratar de uma planta muito útil como industrial frutífera e ornamental é incluída nas listas das plantas com possibilidades de reflorestamento. Seu fruto possui maturação de dezembro á março, possuindo polpa fibrosa e comestível, usada para fazer licores, vinhos e preparo de cachaça. A amêndoa da semente fornece azeite alimentar e também é possível extrair o seu óleo essencial (REITZ et al., 1988).

Os óleos essenciais constituem produtos que podem ultrapassar 300 componentes químicos diferentes. Tal diversidade e complexidade fazem dos óleos essenciais produtos com aplicação em diversas áreas, como na saúde devido ao seu potencial terapêutico, perfumaria, cosmética e química, devido a sua refinada e complexa composição aromática, na área alimentícia devido ao seu potencial como aditivo flavorizante, aromatizante, e produtos domosanitários, e a na moda, confeccionando fibras onde os óleos essenciais inicialmente retidos vão sendo liberados na medida da utilização das peças em couro, bolsas, cintos e roupas (WOLFFENBÜTTEL, 2007; FERNANDES et al., 2013). 
Devido aos óleos que compõem suas amêndoas, as palmeiras do gênero Butiá capitata apresentam-se como uma alternativa de alto valor energético com potencial para produção de óleos de alta produtividade e rentabilidade (CAETANO, 2006). Tem-se mostrado maior interesse em pesquisas, também aumentando a produção de frutos e sementes oleaginosas, tanto para a indústria oleoquímica, como para a alimentícia, a qual utiliza a $80 \%$ da produção mundial (LAURELES et al., 2002). O óleo essencial da amêndoa do Butiá capitata tem um considerável potencial em aplicações industriais, devido ao fato de apresentar significativa atividade antimicrobiana contra bactérias orais e por ser rico em ácidos graxos de cadeia média e longa (ácidos: láurico, miristico, caprílico, araquidônico, oléico e linoléico) (HUANG, 2010).

O objetivo do presente trabalho foi avaliar a extração do óleo da amêndoa do Butiá capitata pelo método de Soxhlet, variando-se fatores distintos como tempo de extração e solvente, visando através dos mesmos avaliar a maior rentabilidade de óleo.

\section{MATERIAL E MÉTODOS}

Os ensaios das extrações de óleo essencial da amêndoa do Butiá capitata procederam-se no Laboratório de Química Geral da Universidade Comunitária da Região de Chapecó (UNOCHAPECÓ). Os frutos eram provenientes de uma palmeira do gênero Butiá capitata localizada no município de Erechim (RS), colhidos quando maduros.

Primeiramente, higienizou-se os frutos e separou-se manualmente a polpa do caroço, este último foi quebrado para a retirada da amêndoa. As amêndoas foram então trituradas em liquidificador e secas ao ar livre com temperatura ambiente de aproximadamente $30^{\circ} \mathrm{C}$ por 24 horas. Colocou-se 3,00 gramas de amêndoa do fruto de Butiá capitata moída e seca dentro de um papel filtro, o qual foi inserido no Soxhlet conforme metodologia proposta pelo Instituto Adolfo Lutz (2008). Logo após, adicionou-se $150 \mathrm{~mL}$ de solvente em um balão volumétrico de fundo chato. O óleo com o solvente depositados no balão volumétrico de fundo chato, após o fim da extração, foram retirados do extrator e encaminhados para um rota evaporador do modelo TE-211 da marca TECNAL para retirar o excesso de solvente, em seguida pesou-se a amostra para o cálculo do rendimento. A variação do solvente e tempo de extração foram realizados de acordo com o planejamento fatorial completo $2^{2}$, em duplicata, conforme pode ser observado na Tabela 1 .

Os resultados obtidos foram tratados no software Statistica 7, submetidos à análise de variância (ANOVA), ao nível de 5\% significância.

\section{RESULTADOS E DISCUSSÃO}

A Tabela 1 apresenta os resultados obtidos pelo planejamento fatorial completo $2^{2}$. Pode-se observar que o maior rendimento da extração de óleo da amêndoa do Butiá capitata foi obtido nos níveis positivos de cada fator analisado, ou seja, 60 minutos e etanol, obtendose um rendimento médio de $38,80 \%$. 
Tabela 1 - Resultados obtidos a partir de duplicata da matriz de planejamento para extração do óleo da amêndoa do Butiá capitata com valores reais e codificados

\begin{tabular}{cccccccc}
\hline Ensaios & $\mathbf{X}_{\mathbf{1}}$ & $\mathbf{X}_{\mathbf{2}}$ & $\begin{array}{c}\text { Tempo } \\
\text { (minutos) }\end{array}$ & Solvente & $\begin{array}{c}\text { Rendimento } \\
\mathbf{( \% )}\end{array}$ & $\begin{array}{c}\text { Média } \\
(\mathbf{\%})\end{array}$ \\
\hline $\mathbf{1}$ & -1 & -1 & 30 & Hexano & 22,90 & 24,01 & 23,46 \\
$\mathbf{2}$ & +1 & -1 & 60 & Hexano & 30,59 & 30,43 & 30,51 \\
$\mathbf{3}$ & -1 & +1 & 30 & Etanol & 36,14 & 37,58 & 36,86 \\
$\mathbf{4}$ & +1 & +1 & 60 & Etanol & 38,45 & 39,15 & 38,80 \\
\hline
\end{tabular}

Através dos dados da Tabela 1, determinam-se quais parâmetros são significativos para a extração do óleo, conforme a Tabela 2, onde t representa o tempo e S o solvente.

Tabela 2 - Coeficientes de regressão, erro padrão, $t$ (4) e p-valor para o planejamento fatorial completo $2^{2}$

\begin{tabular}{ccccc}
\hline Fatores & $\begin{array}{c}\text { Coeficiente de } \\
\text { Regressão }\end{array}$ & Erro padrão & $\boldsymbol{t}(\mathbf{4 )}$ & p-valor \\
\hline Média & 32,46937 & 0,229220 & 141,6517 & 0,000000 \\
$\mathbf{1 ~ t}$ & 2,31062 & 0,229220 & 10,0804 & 0,000545 \\
$\mathbf{2} \mathbf{S}$ & 5,48688 & 0,229220 & 23,9372 & 0,000018 \\
$\mathbf{1}$ by $\mathbf{2}$ & $-1,21687$ & 0,229220 & $-5,3088$ & 0,006051 \\
\hline
\end{tabular}

Como pode ser verificado na Tabela 2 o tempo de extração, tipo de solvente e a interação entre os mesmos são significativos na extração do óleo, pois apresentaram o $p<0,05$ (RODRIGUES e IEMA, 2005). A partir destes resultados, obteve-se o modelo codificado conforme a Equação 1.

Rendimento $(\%)=32,47+2,31 t+5,49 S-1,22 t S$ 
A Tabela 3 apresenta a análise de variância (ANOVA) através da qual analisou-se a qualidade de ajuste do modelo codificado representado na Equação 1.

Tabela 3 - Análise de variância (ANOVA)

\begin{tabular}{ccccc}
\hline $\begin{array}{c}\text { Fonte de } \\
\text { Variação }\end{array}$ & SQ & GL & MQ & Fcalculado \\
\hline Regressão & 295,4047 & 3 & 98,4682 & 234,28 \\
Resíduo & 1,6813 & 4 & 0,4203 & \\
Total & 297,086 & 7 & & \\
\hline
\end{tabular}

$\mathrm{F}_{3,4,95 \%}=6,59 ; \mathrm{R}^{2}=99,43$

Conforme demonstra a Tabela 3, o valor de F calculado é igual a 234,28 sendo este um valor aproximadamente 35 vezes maior do que o $\mathrm{F}$ tabelado de valor 6,59 (RODRIGUES e IEMA, 2005). Por isto, assumiu-se que o modelo representado pela Equação 1 é preditivo. $\mathrm{O}$ valor obtido de $\mathrm{R}^{2}$ foi igual a 99,43 , ou seja, o modelo explica $99,43 \%$ das respostas preditas pelo mesmo.

Verificando a Figura 1, pode-se observar o ponto em que o rendimento atingiu seu máximo valor foi com o maior tempo de extração e o solvente etanol. Nota-se que o rendimento atingiu seu mínimo quando utilizado o hexano no menor tempo de extração.

Figura 1 - Rendimento de óleo relacionando o tempo de extração e o tipo de solvente. 

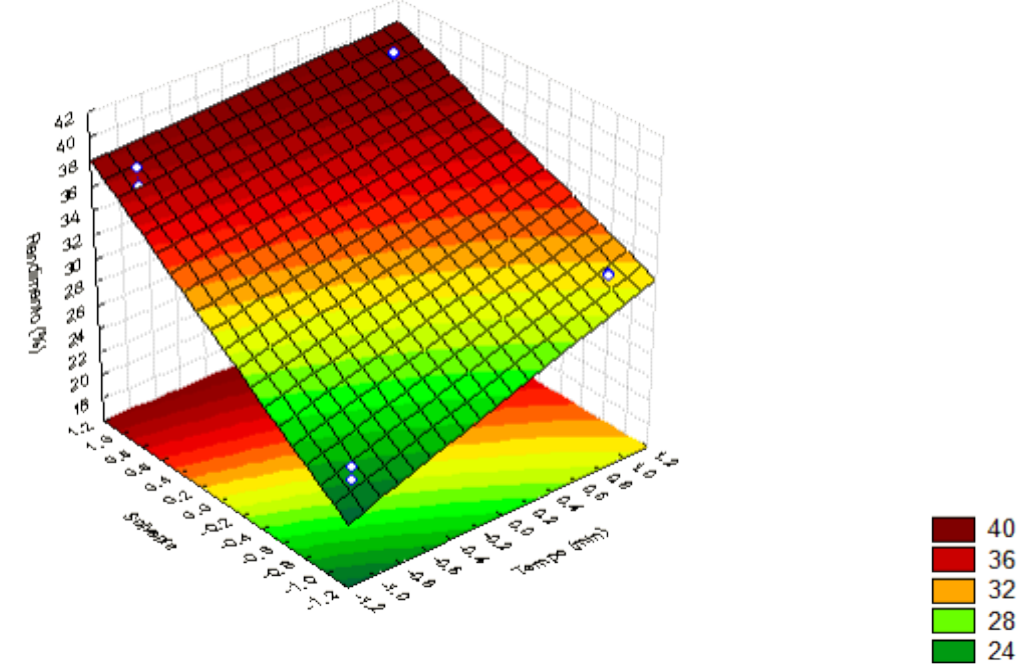

\section{CONCLUSÃO}

Conclui-se que o objetivo da extração do óleo da amêndoa do Butiá capitata foi alcançado, dado que conseguiu-se 38,80 \% de rendimento de óleo, nos ensaios com etanol e 60 minutos de extração. O modelo codificado obtido foi preditivo, explicando $99,43 \%$ das respostas obtidas pelo mesmo, gerando previsões confiáveis nos níveis trabalhados neste estudo.

Cabe ressaltar que o rendimento foi satisfatório para todos os valores de extração, mesmo trabalhando com 30 minutos e solvente hexano, pois se trata de uma matéria prima, amêndoa do caroço, que não é utilizada industrialmente quando trabalha-se apenas com a polpa, e se o fruto for disponibilizado inteiro ao consumidor, este também despreza o caroço. A caracterização qualitativa e quantitativa do óleo está em andamento, pois espera-se que este tenha possíveis aplicações na indústria química, farmacêutica e de alimentos, que prevê como principal objetivo o desenvolvimento de novos produtos.

\section{REFERÊNCIAS}

CAETANO, M. O desafio do biodiesel. Glob. Rur. São Paulo, n.253. p.40- 49. 2006.

HUANG, C. B.; GEORGE, B.; EBERSOLE, J. L. Antimicrobial activity n-6, n-7 and n-9 fatty acids and their esters for oral microorganisms. Arch. Oral Biol., v.8, n.55, p.555-560, 2010 . 
FERNANDES, R. V. B; BORGES, S. V.; Diego Alvarenga BOTREL, D. A. Influence of spray drying operating conditions on microencapsulated rosemary essential oil properties. Ciênc. Tecnol. Aliment., Campinas, 33(Supl. 1): 171-178, fev. 2013.

INSTITUTO ADOLFO LUTZ. Normas Analíticas do Instituto Adolfo Lutz. v.1: Métodos Químicos e Físicos para análises de alimentos, 4.ed. São Paulo : IMESP.2008.

LAURELES, L. R.; RODRIGUEZ, F. M.; REANO, C. E.; SANTOS, G. A.; LAURENA, A. C.; MENDOZA, E. M. T. Variability in fatty acid and triacylglycerol composition of the oil of coconut (Cocos nucifera L.) hybrids and their parentals. J. Agric. Food Chem., Davis, v. 50, p. 1581-1586, 2002.

REITZ, R.; KLEIN, M. R.; REIS, A. Projeto madeira do Rio Grande do Sul. edt: COMPANIA RIO GRANDENSE DE ARTES GRÁFICAS (CORAG), 1988, 379p.

RODRIGUES, M. I.; IEMMA, A. F. Planejamento de experimentos e otimização de processos: uma estratégia sequencial de planejamentos. Campinas, SP: Casa do pão editora, 2005. 325p. ISBN 859838903 X (broch).

WOLFFENBÜTTEL, N. A. Óleos essenciais: extração, importância e aplicações no cotidiano. Artigo publicado no informativo crq-v, ano xi, n. ${ }^{\circ} 105$, novembro/dezembro/2007, págs. 06 e 07. 